Article

\title{
Development of a Surface-Functionalized Titanium Implant for Promoting Osseointegration: Surface Characteristics, Hemocompatibility, and In Vivo Evaluation
}

\author{
Ping-Jen Hou ${ }^{1,2}$, Syamsiah Syam ${ }^{2,3}{ }^{(\mathbb{D}}$, Wen-Chien Lan ${ }^{4}$, Keng-Liang Ou ${ }^{2,4,5,6,7} \mathbb{1}$, \\ Bai-Hung Huang ${ }^{2,8,9}$, Ka-Chun Chan ${ }^{10}$, Chi-Hsun Tsai ${ }^{6}$, Takashi Saito ${ }^{6}{ }^{\circ}$, Chung-Ming Liu ${ }^{2,3}$, \\ Hsin-Hua Chou 11,12, Yueh-Tzu Huang ${ }^{2,13, *}$ and Fang-Yu Fan 2,14,*(D) \\ 1 Graduate Institute of Biomedical Materials and Tissue Engineering, College of Biomedical Engineering, \\ Taipei Medical University, Taipei 110, Taiwan; D825104002@tmu.edu.tw \\ 2 Biomedical Technology R \& D Center, China Medical University Hospital, Taichung 404, Taiwan; \\ u108312101@cmu.edu.tw (S.S.); klou@tmu.edu.tw (K.-L.O.); T33782@mail.cmuh.org.tw (B.-H.H.); \\ liuc@mail.cmu.edu.tw (C.-M.L.) \\ 3 Graduate Institute of Dental Science, College of Dentistry, China Medical University, Taichung 404, Taiwan \\ 4 Department of Oral Hygiene Care, Ching Kuo Institute of Management and Health, Keelung 203, Taiwan; \\ jameslan@ems.cku.edu.tw \\ 5 Department of Dentistry, Taipei Medical University-Shuang Ho Hospital, New Taipei City 235, Taiwan \\ 6 Division of Clinical Cariology and Endodontology, Department of Oral Rehabilitation, School of Dentistry, \\ Health Sciences University of Hokkaido, Hokkaido 061-0293, Japan; e526095019@tmu.edu.tw (C.-H.T.); \\ t-saito@hoku-iryo-u.ac.jp (T.S.) \\ 7 3D Global Biotech Inc. (Spin-off Company from Taipei Medical University), New Taipei City 221, Taiwan \\ 8 Asia Pacific Laser Institute, New Taipei City 220, Taiwan \\ 9 Implant Academy of Minimally Invasive Dentistry, Taipei 106, Taiwan \\ 10 Academy of Oral Implantology, Taipei 105, Taiwan; d204095002@tmu.edu.tw \\ 11 School of Dentistry, College of Oral Medicine, Taipei Medical University, Taipei 110, Taiwan; \\ hhchou@tmu.edu.tw \\ 12 Dental Department of Wan-Fang Hospital, Taipei Medical University, Taipei 116, Taiwan \\ 13 Division of Family and Operative Dentistry, Department of Dentistry, Taipei Medical University Hospital, \\ Taipei 110, Taiwan \\ 14 School of Dental Technology, College of Oral Medicine, Taipei Medical University, Taipei 110, Taiwan \\ * Correspondence: 997184@h.tmu.edu.tw (Y.-T.H.); fish884027@tmu.edu.tw (F.-Y.F.)
}

Received: 29 October 2020; Accepted: 27 November 2020; Published: 30 November 2020

\begin{abstract}
This study aimed to evaluate the impact of surface-modified biomedical titanium (Ti) dental implant on osseointegration. The surfaces were modified using an innovative dip-coating technique (IDCT; sandblasted, large-grit, and acid-etched, then followed by coating with the modified pluronic F127 biodegradable polymer). The surface morphology and hemocompatibility evaluations were investigated by field-emission scanning electron microscopy, while the contact analysis was observed by goniometer. The IDCT-modified Ti implant was also implanted in patients with missing teeth by single-stage surgical procedure then observed immediately and again four months after placement by cone-beam computerized tomography (CBCT) imaging. It was found that the IDCT-modified Ti implant was rougher than the dental implant without surface modification. Contact angle analysis showed the IDCT-modified Ti implant was lower than the dental implant without surface modification. The hemocompatibility evaluations showed greater red blood cell aggregation and fibrin filament formation on the IDCT-modified Ti implant. The radiographic and CBCT image displayed new bone formation at four months after the IDCT-modified Ti implant placement. Therefore, this study suggests that the IDCT-modified Ti dental implant has great potential to accelerate osseointegration.
\end{abstract}


Keywords: dip-coating; dental implant; biodegradable polymer; osseointegration

\section{Introduction}

The use of dental implants for the rehabilitation of missing teeth is increasingly popular because it resembles natural teeth both in terms of function and aesthetics [1-6]. The success of dental implants is indicated by its survival rate as a consequence of the osseointegration, which is based on various factors originating from the patient, clinician, implant placement area, and characteristics of the implant $[1,4]$. The success of a dental implant after placement can also be determined by the stability of the implant, minimal signs and symptoms, new bone formation, and healthy tissue around the implant [7].

Dental implants used to rehabilitate missing teeth are derived from titanium (Ti), which has advantageous properties such as resistance to corrosion, high strength, and excellent biocompatibility [5,8-11]. However, the properties of Ti have not met the criteria for clinical use. Therefore, various surface modifications were performed on $\mathrm{Ti}$, such as plasma spray coating, ion implantation, laser, sputtering, acid etching, sandblasting, sandblasting and acid etching, and dip coating, to improve the quality of its biological, chemical, and mechanical properties [12-14]. Surface modification aims to provide an implant surface that can be accepted by the surrounding tissue (a good bone-implant interaction) to create osseointegration leading to the successful placement of dental implants [6,10,15-19].

Sandblasted, large-grit, and acid-etched (SLA) technique is a surface modification that has shown successful long-term clinical outcomes [11,20]. However, dental implant failures still persist with failure rates varying from $1 \%$ to $19 \%$ due to inadequate osseointegration and the occurrence of implantitis after implant placement [21,22]. Thus, various efforts were performed to minimize the risk of implant failure, such as performing the appropriate surgical technique, providing enough bone quality and quantity, minimizing the inflammation or infection after surgery, modifying the surface modification, and improving of patient nutrition by providing several dietary supplements that affect bone metabolism, all of which lead to osseointegration $[19,23]$. However, the current study is focused on modifying the surface modification of Ti dental implants. In this study, the dental implants that have received SLA surface modification are followed by coating with pluronic F127 (PF127). Pluronic is an active polymer that has good biocompatibility, low cost, easy preparation, biodegradability, and is nontoxic, making it widely used in biomedical applications [24-26]. Therefore, this study aimed to evaluate the impact of the surface properties of the surface-modified Ti dental implants on osseointegration through surface morphology, contact angle analysis, hemocompatibility evaluation, and clinical evaluations. It is believed that the surface-modified Ti dental implant is able to create rapid osseointegration with good biocompatibility, and will lead to the clinical success of dental implants in terms of rehabilitation of missing teeth.

\section{Materials and Methods}

\subsection{Materials}

Dental implant used in this study is grade 4 pure Ti material. The dental implant was surface-modified by means of an innovative dip-coating technique (IDCT), as shown in Figure 1. The Ti implant was grit-blasted with aluminum oxide $\left(\mathrm{Al}_{2} \mathrm{O}_{3}\right)$ particles followed by acid-etching in hydrochloric acid and sulfuric acid solutions, then washed. Subsequently, the Ti implant was coated with the modified-PF127 biodegradable polymer (MPBP) through the IDCT process. The MPBP was prepared using the N-hydroxysuccinimide end-labeled F127 block copolymer (Sigma $0.033 \mathrm{mmol}$, Taipei, Taiwan), triethylamine (Sigma $0.218 \mathrm{mmol}$, Taipei, Taiwan), and $2.6 \mathrm{~mL} \mathrm{~N}$, $\mathrm{N}$-dimethylformamide (DMF; Sigma, Taipei, Taiwan). Afterward, the mixed solution was stirred with a magnetic stirring bar at $25^{\circ} \mathrm{C}$ for $16 \mathrm{~h}$ under nitrogen atmosphere. The reacted mixture solution 
was then freeze-dried to remove the DMF. Afterward, chilled methanol was added in the reacted mixture solution without DMF to form the precipitate solution. Finally, the precipitate solution was filtered and dried under a high vacuum pressure to form the MPBP. This process was performed by immersing the Ti implant into the MPBP solution at $4{ }^{\circ} \mathrm{C}$ for $15 \mathrm{~min}$ and drying in an oven at $30^{\circ} \mathrm{C}$ for $5 \mathrm{~h}$. The machined Ti implant was used as a control for comparison in surface characteristic observation and hemocompatibility assay, while the SLA-treated Ti implant was used as a control for contact angle analysis.

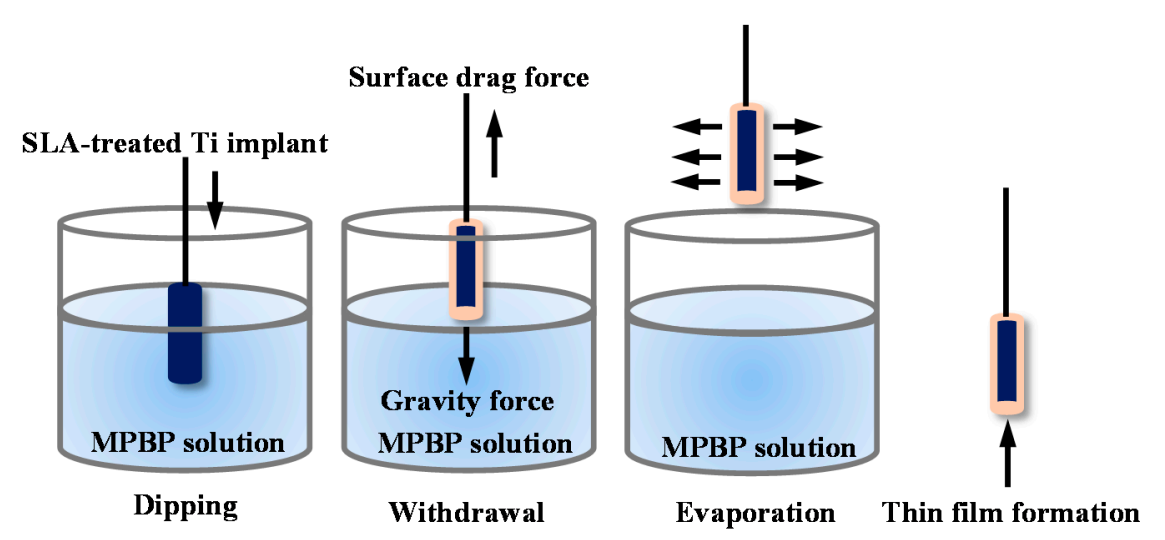

Figure 1. A schematic diagram showing the experimental setup used for surface modification of titanium (Ti) dental implant. (sandblasted, large-grit, and acid-etched (SLA) and modified-PF127 biodegradable polymer (MPBP))

\subsection{Surface Characteristic Observation}

Surface morphology and characteristics of the Ti implant with and without surface modification were observed using a JSM-6500F field-emission scanning electron microscope (FE-SEM; JEOL Ltd., Tokyo, Japan) under an accelerating voltage of $25 \mathrm{kV}$. Before investigation, a platinum thin film with a thickness of $30 \mathrm{~nm}$ was sputter-coated on the surface of implants to enhance electrical conductivity.

\subsection{Contact Angle Analysis}

The angle of point contact of a line tangent to the liquid and the surface of the Ti implant (contact angle) was analyzed by the sessile drop method. A $0.05 \mathrm{~mL}$ droplet (deionized water) was dropped onto the Ti implant surface, the distance of dropping was kept constant at $10 \mathrm{~mm}$, and the profile of the droplet observed by GBX digidrop goniometer (Drôme, France).

\subsection{Hemocompatibility Assay}

The Ti implants were initially sterilized with ethylene oxide for $24 \mathrm{~h}$. Thereafter, the implant was placed in centrifuge tubes, dripped with $100 \mu \mathrm{L}$ blood, and clotted at $25{ }^{\circ} \mathrm{C}$ for $20 \mathrm{~min}$. The uncoagulated blood from Ti implant surfaces was cleaned by immersing it in deionized water at $25^{\circ} \mathrm{C}$ for $10 \mathrm{~min}$. Finally, the investigated implants were fixed in $2 \%$ glutaraldehyde solution, washed, rinsed, sputter coated with $30 \mathrm{~nm}$ of platinum, and analyzed using FE-SEM.

\subsection{Clinical Evaluations}

The protocols for clinical evaluations were approved by the Taipei Medical University-Joint Institutional Review Board under the project identification code of TMU-JIRB 201301009. The good clinical practice was followed together with ISO 14155 prescriptions during the clinical study. A single-stage surgical procedure was conducted under local anesthesia, followed by the incision of crestal mucoperiosteal. A full-thickness mucoperiostal flap was reflected (Figure 2a), the IDCT-modified Ti implant ( $n=15$, different size implants) placed into the socket (Figure $2 b)$, the flap replaced, and 
the surgical area sutured (Figure 2c). The CBCT image was taken immediately and then four months after placement.
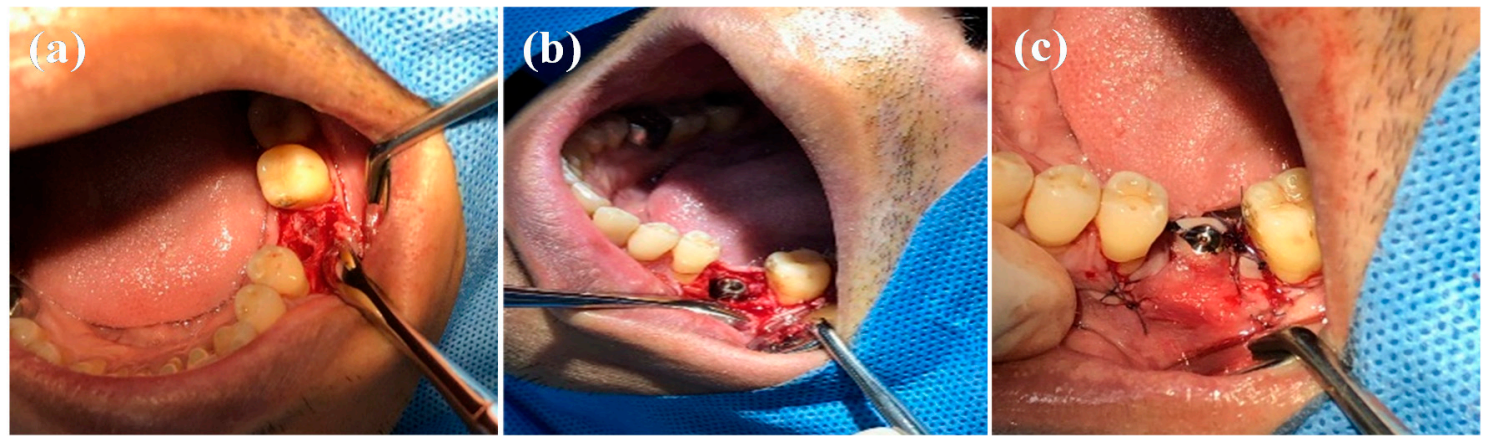

Figure 2. Surgical procedure of the innovative dip-coating technique (IDCT)-modified Ti dental implant: (a) mucoperiostal flap reflection, (b) dental implant placement, and (c) suturing surgical area.

\section{Results}

\subsection{Topographic Features of the IDCT-Modified Ti Implant}

Figure 3 shows superficial FE-SEM micrographs of the investigated implants. Obviously, the Ti implant without modification revealed regular machining grooves surface (Figure 3a). After conducting the IDCT process, a more rough, uniform, and small micropitted surface morphology generated by SLA treatment was observed on the Ti implant surface, as revealed in Figure 3b. The MPBP coating did not change the topographic features of the SLA-treated Ti implant during the IDCT process because the MPBP is a polymeric material.
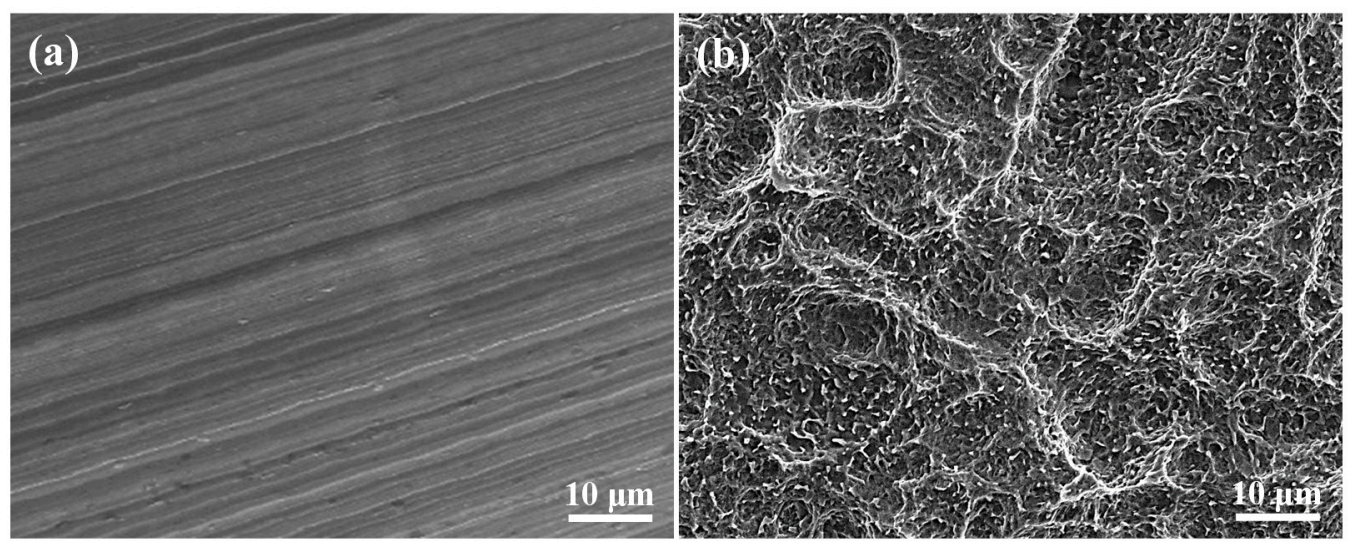

Figure 3. The field-emission scanning electron microscope (FE-SEM) images of the investigated Ti implants: (a) control Ti implant; (b) IDCT-modified Ti implant.

\subsection{Wettability of the IDCT-Modified Ti Implant}

Figure 4 presents contact angle images taken from the Ti implant with SLA and IDCT modifications. The contact angle values were measured as $70^{\circ}$ on Ti implant with typical SLA modification (Figure 4a), while the contact angle of Ti implant with IDCT surface modification was $0^{\circ}$ (Figure $4 \mathrm{~b}$ ). This finding indicated that the IDCT-modified Ti implant possessed a super hydrophilic surface. 
(a)

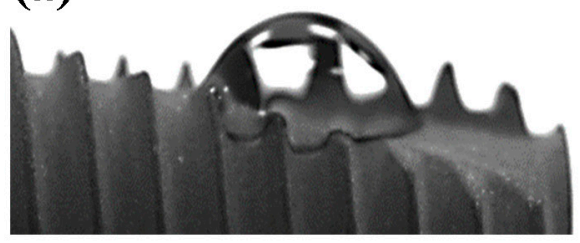

(b)

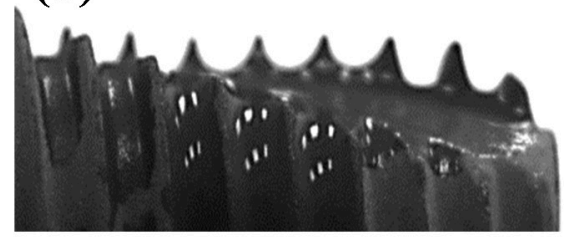

Figure 4. The wettability of the Ti implant with different surface modifications: (a) typical SLA modification; (b) IDCT modification.

\subsection{Hemocompatibility of the IDCT-Modified Ti Implant}

Figure 5 displays the FE-SEM micrographs of red blood cell (RBC) morphology upon Ti implant with and without surface modification. Obviously, less RBC aggregation was seen on Ti implants without surface modification (Figure 5a), while the IDCT-modified Ti implants showed an implant surface rich in RBC aggregation and fibrin filament formation (Figure $5 b$ ).

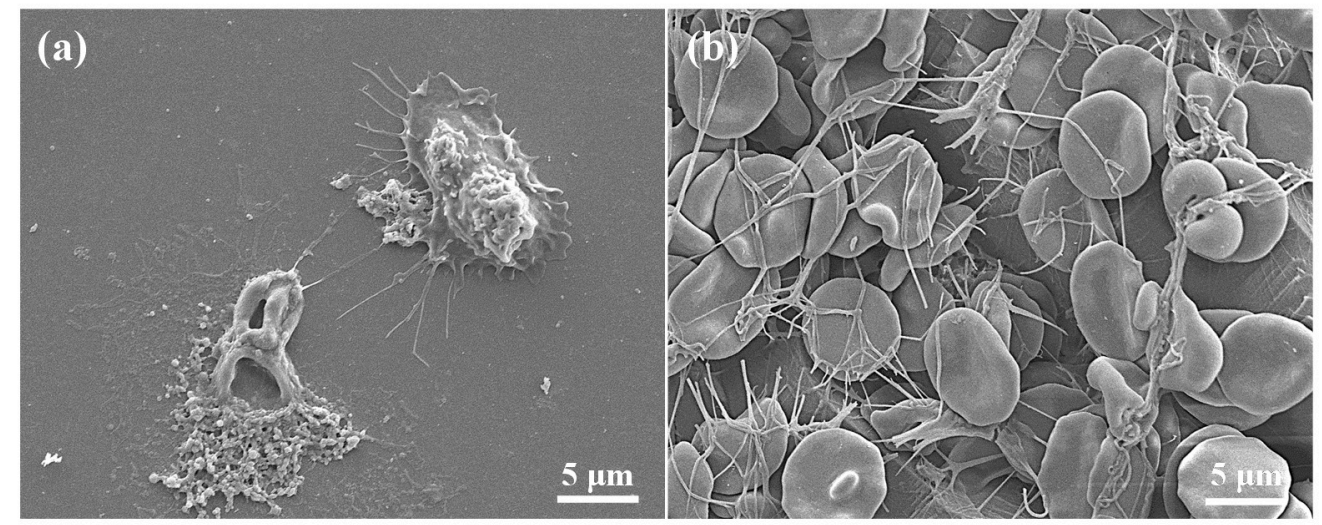

Figure 5. The FE-SEM micrographs of red blood cell morphology on the (a) unmodified Ti implant and (b) IDCT-modified Ti implant.

\subsection{Clinical Evaluations of the IDCT-Modified Ti Implant}

The CBCT image taken from the IDCT-modified Ti implant after immediate placement is shown in Figure 6a. The CBCT image revealed a radiolucency in the buccal dental implant site (as indicated by the black arrow), indicating that the site is unsupported by intact bone. After four months of post-placement, the $\mathrm{CBCT}$ image showed a more radiopaque image of the buccal dental implant site (Figure 6b, black arrow), which previously appeared more radiolucent, indicating new bone formation in this area. Moreover, the clinical condition after four months also indicated that good tissue healing around the IDCT-modified Ti implant was evident, as illustrated in Figure 6c.
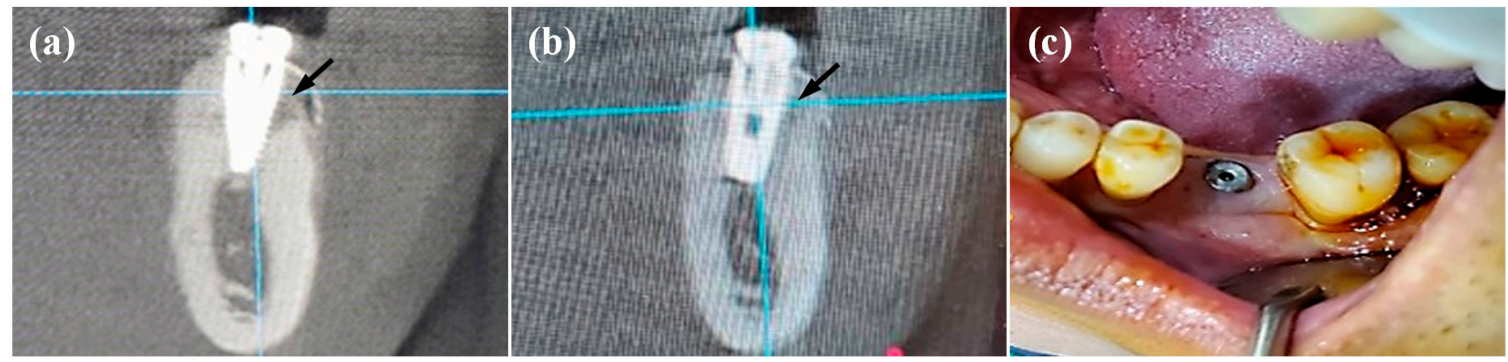

Figure 6. The cone-beam computerized tomography images taken from the left mandibular premolar with the IDCT-modified Ti implant after (a) immediate placement, (b) four months placement, and (c) clinical evaluation (four months placement). 
Similar findings were also observed in other patients with the IDCT-modified Ti implant treatment. The follow-up after four months showed a radiologically and clinically health condition reflected by no further bone loss found around the dental implant (Figures 7 and 8).

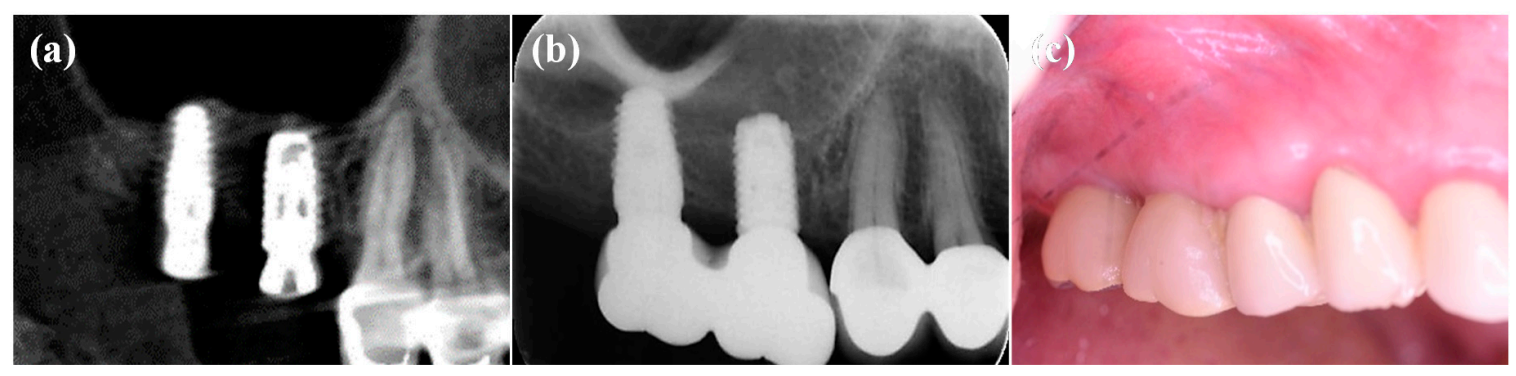

Figure 7. The radiographic images taken from the right maxillary molar with the IDCT-modified Ti implant after (a) immediate placement, (b) four months placement, and (c) clinical evaluation (four months placement).

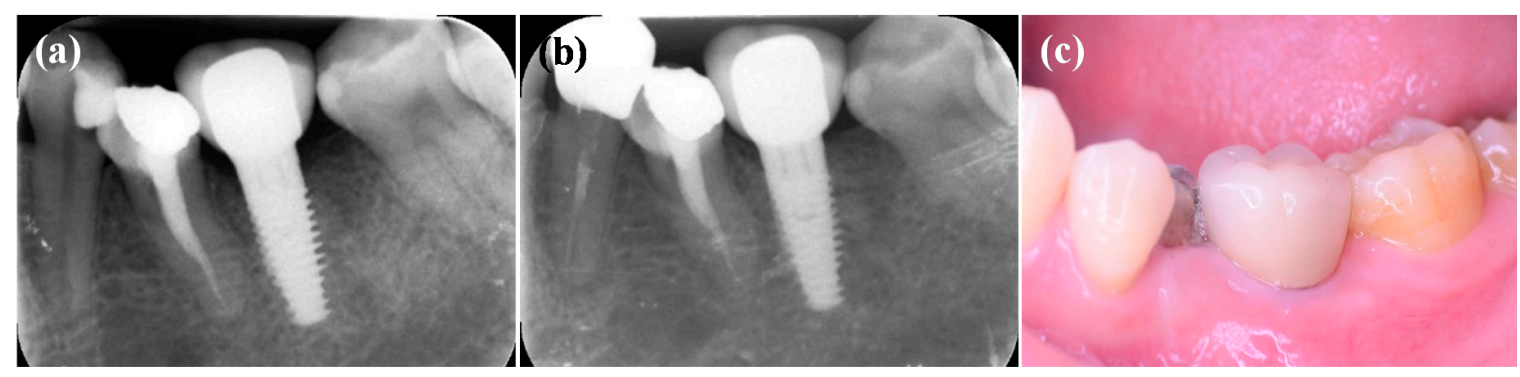

Figure 8. The radiographic images taken from the left mandibular premolar with the IDCT-modified Ti implant after (a) one-month placement, (b) four months placement, and (c) clinical evaluation (four months placement).

\section{Discussion}

The success of dental implant placement related to their biocompatibility and hemocompatibility. Acceptable biocompatibility and hemocompatibility can be obtained by performing various surface modifications of dental implants. The surface modification results in a roughness of the implant surface, which will affect its survival rate even if it has been placed in a deficient jawbone. The roughness and porosity of the dental implant will become a scaffold for bone growth, which will increase its fixation in the jaw [9,27-30]. The pores of surface-modified dental implants can be a place for cell and tissue growth and allow the diffusion of various nutrients. The SLA surface modification provides an ideal porosity for cell adhesions [11]. The SLA surface modification that provides macro- and microporosity will increase the contact angle and hydrophilicity of the dental implant surface, allowing migration of osteoblasts and tissue into the implant, leading to improved integration between the implant and the surrounding tissue $[8,11,17,31-33]$. The survival rate of dental implants with SLA surface modification can reach $99 \%$ with a mean follow-up period of 18 months [27]. The main advantage of surface modification with modified PF127 is that it resembles an extracellular matrix of various tissues that will facilitate cell adhesion and proliferation [24].

Contact angles that arise from the combination of surface tension of the liquid and surface energy of solid implant material are associated with hydrophilicity or wetting behavior, which will increase the interaction of dental implants with biological fluids, cells, and tissues [8,9,34,35]. The lower contact angle indicates better wettability on the dental implant surface [34]. Various surface modifications are performed to roughen the surface of the dental implants that can affect its wettability. Several studies have shown the dental implants that obtain SLA surface modification have a hydrophilic surface with a contact angle that varies from $40^{\circ}$ to $70^{\circ}$ [32]. However, this study revealed that the contact angle of the IDCT-modified Ti implant was $0^{\circ}$, which indicates all the liquid completely spread over the 
modified surface [32]. The increase in wettability on the IDCT-modified Ti implant surface is due to the surface coating with biodegradable polymer PF127, which with its hydrophilic properties has the ability to absorb various biological fluids [36,37].

The RBC aggregation was also influenced by wettability behavior on the surface of the $\mathrm{Ti}$ implant $[18,38,39]$. In biomedical Ti dental implants, the surface hydrophilicity increases, allowing the absorption of various plasma proteins such as fibrinogen, which is necessary for the healing process and the formation of new bone around the implant $[18,38-40]$.

The porosity of the implant surface can also serve to reduce the stiffness of the implant material. At a minimum, Young's modulus of the implant material resembles bone to prevent bone resorption around the implant [28]. Nevertheless, it has been reported that the rougher the surface of the dental implant, the greater the potential for bacterial adhesion to the surface of the dental implant through biofilm formation [5,41]. Immediately after implant placement, some proteins will bind to the surface of the implant to create an optimal area for cell attachment, both favorable and harmful cells (bacteria). The large number of bacterial colonies formed will cause various conditions that are unfavorable for implants, such as inflammation, implantitis, and inhibition of osseointegration, which lead to implant failure $[5,41,42]$. Therefore, the use of modified biodegradable polymer PF127 in the surface modification of dental implants in this study has several advantages, apart from resembling an extracellular matrix, its amphiphilic properties, which act as surfactants exhibiting antibacterial action. The modified PF127 consists of triblock poly (ethylene oxide) (PEO)-poly (propylene oxide) (PPO)-poly (ethylene oxide) (PEO) [36,43-45]. The hydrophilic PEO will bind to the hydrophilic membrane via hydrogen bonds, while hydrophobic PPO will penetrate the lipid bilayer structure, causing the disruption of membrane permeability and biosynthesis of the bacterial cell wall $[45,46]$. Moreover, PF127 is biodegradable; new bone growth and angiogenesis will be created as a consequence of its degradation [26,47-49].

The success of dental implants is marked by the presence of new bone formation and healthy tissue around dental implants. Del Fabro et al. [7] reported that of a total of 135 dental implants that reported failure, $60.9 \%$ occurred in the first six months after implant placement. In our study, there were no signs and symptoms complained of by the patients, and the clinical condition showed healthy gingival tissue around the implant at follow-up four months after implant placement. Moreover, both radiographic and CBCT images showed the presence of new bone formation around the implant. Thus, the IDCT-modified Ti dental implants might be beneficial for osseointegration that led to successful dental implants. However, a further study is needed for clinical application, with a larger sample size and a varied follow-up period to strengthen the evidence of the rapid osseointegration resulting from dental implants.

\section{Conclusions}

The surface morphology observation indicated that the IDCT-modified Ti implant is rougher than Ti implant without surface modification. The contact angle analysis of the IDCT-modified Ti implant exhibited excellent wettability performance. In hemocompatibility evaluations, the IDCT-modified Ti implant revealed greater RBC aggregation, which is important for the healing process and the formation of new bone around the implant. The $\mathrm{CBCT}$, radiographic, and clinical evaluations prove the new bone formation around the IDCT-modified Ti implant after implantation of four months. Accordingly, these findings demonstrate the IDCT-modified Ti implant had great potential to promote bone regeneration for dental applications.

Author Contributions: Investigation, P.-J.H.; resources, S.S.; methodology, K.-C.C. and B.-H.H.; data curation, C.-H.T. and W.-C.L.; supervision; K.-L.O. and T.S.; validation, C.-M.L. and H.-H.C.; writing-original draft, P.-J.H.; writing-review and editing, Y.-T.H. and F.-Y.F. All authors have read and agreed to the published version of the manuscript.

Funding: This research received no external funding. 
Acknowledgments: The authors would like to thank the T-Plus Implant Tech. Co., Ltd. for technical support. The authors would also like to thank Dr. Chi-Chung Lo for his helpful advice and technical support on clinical evaluations examined in this paper.

Conflicts of Interest: The authors declare no conflict of interest.

\section{References}

1. Levin, L. Dealing with dental implant failures. J. Appl. Oral Sci. 2008, 16, 171-175. [CrossRef] [PubMed]

2. Manaf, J.B.A.; Rahman, S.A.; Haque, S.; Alam, M.K. Bacterial Colonization and Dental Implants: A Microbiological Study. Pesqui. Bras. Odontopediatria Clínica Integr. 2020, 20. [CrossRef]

3. Maiorana, C.; Andreoni, D.; Polacco, P.; Poli, P.P. Multidisciplinary Oral Rehabilitation of a Severely Compromised Dentition. Case Rep. Dent. 2020, 2020, 2429505. [CrossRef] [PubMed]

4. Zarean, P.; Zarean, P.; Kanounisabet, N.; Moghareabed, A.; Rismanchian, M.; Yadegarfar, G. Dental Implant Rehabilitation in Patients Suffering from Mucocutaneous Diseases: A Systematic Review and Meta-Analysis. Open Dent. J. 2018, 12, 873-883. [CrossRef]

5. Siddiqui, D.A.; Jacob, J.J.; Fidai, A.B.; Rodrigues, D.C. Biological characterization of surface-treated dental implant materials in contact with mammalian host and bacterial cells: Titanium versus zirconia. RSC Adv. 2019, 9, 32097-32109. [CrossRef]

6. Mandracci, P.; Mussano, F.; Rivolo, P.; Carossa, S. Surface Treatments and Functional Coatings for Biocompatibility Improvement and Bacterial Adhesion Reduction in Dental Implantology. Coatings 2016, 6, 7. [CrossRef]

7. Del Fabbro, M.; Testori, T.; Kekovic, V.; Goker, F.; Tumedei, M.; Wang, H.L. A Systematic Review of Survival Rates of Osseointegrated Implants in Fully and Partially Edentulous Patients Following Immediate Loading. J. Clin. Med. 2019, 8, 2142. [CrossRef]

8. Kim, I.-H.; Kwon, T.-Y.; Kim, K.-H. Wetting Behavior of Dental Implants; IntecOpen: London, UK, 2015.

9. Luers, S.; Seitz, C.; Laub, M.; Jennissen, H.P. Contact Angle Measurement on Dental Implants. Biomed. Tech. 2014, 59, 4. [CrossRef]

10. Ting, M.; Jefferies, S.R.; Xia, W.; Engqvist, H.; Suzuki, J.B. Classification and Effects of Implant Surface Modification on the Bone: Human Cell-Based In Vitro Studies. J. Oral Implant. 2017, 43, 58-83. [CrossRef]

11. Yeo, I.L. Modifications of Dental Implant Surfaces at the Micro- and Nano-Level for Enhanced Osseointegration. Materials 2019, 13, 89. [CrossRef]

12. Sartoretto, S.C.; Alves, A.T.; Resende, R.F.; Calasans-Maia, J.; Granjeiro, J.M.; Calasans-Maia, M.D. Early osseointegration driven by the surface chemistry and wettability of dental implants. J. Appl. Oral Sci. 2015, 23, 279-287. [CrossRef] [PubMed]

13. Gupta, S.; Dahiya, V.; Shukla, P. Surface topography of dental implants: A review. J. Dent. Implant. 2014, 4, 66. [CrossRef]

14. Hou, P.-J.; Ou, K.-L.; Wang, C.-C.; Huang, C.-F.; Ruslin, M.; Sugiatno, E.; Yang, T.-S.; Chou, H.-H. Hybrid micro/nanostructural surface offering improved stress distribution and enhanced osseointegration properties of the biomedical titanium implant. J. Mech. Behav. Biomed. Mater. 2018, 79, 173-180. [CrossRef] [PubMed]

15. Jung, U.-W.; Hwang, J.-W.; Choi, D.-Y.; Hu, K.-S.; Kwon, M.-K.; Choi, S.-H.; Kim, H.-J. Surface characteristics of a novel hydroxyapatite-coated dental implant. J. Periodontal Implant. Sci. 2012, 42, 59-63. [CrossRef] [PubMed]

16. Le Guéhennec, L.; Soueidan, A.; Layrolle, P.; Amouriq, Y. Surface treatments of titanium dental implants for rapid osseointegration. Dent. Mater. 2007, 23, 844-854. [CrossRef] [PubMed]

17. Letsche, S.A.; Steinbach, A.; Pluntke, M.; Marti, O.; Ignatius, A.; Volkmer, D. Usage of polymer brushes as substrates of bone cells. Front. Mater. Sci. China 2009, 3, 132-144. [CrossRef]

18. Parisi, L.; Toffoli, A.; Cutrera, M.G.; Bianchi, M.; Lumetti, S.; Bussolati, O.; Macaluso, G.M. Plasma Proteins at the Interface of Dental Implants Modulate Osteoblasts Focal Adhesions Expression and Cytoskeleton Organization. Nanomaterials 2019, 9, 1407. [CrossRef]

19. Cervino, G.; Fiorillo, L.; Iannello, G.; Santonocito, D.; Risitano, G.; Cicciù, M. Sandblasted and Acid Etched Titanium Dental Implant Surfaces Systematic Review and Confocal Microscopy Evaluation. Materials 2019, 12, 1763. [CrossRef] 
20. Huang, C.-F.; Chiang, H.-J.; Lin, H.-J.; Hosseinkhani, H.; Ou, K.-L.; Peng, P.-W. Comparison of Cell Response and Surface Characteristics on Titanium Implant with SLA and SLAffinity Functionalization. J. Electrochem. Soc. 2014, 161, G15-G20. [CrossRef]

21. Smeets, R.; Stadlinger, B.; Schwarz, F.; Beck-Broichsitter, B.; Jung, O.; Precht, C.; Kloss, F.; Gröbe, A.; Heiland, M.; Ebker, T. Impact of Dental Implant Surface Modifications on Osseointegration. BioMed Res. Int. 2016, 2016, 6285620. [CrossRef]

22. Do, T.A.; Le, S.H.; Shen, Y.-W.; Huang, H.-L.; Fuh, L.-J. Risk Factors related to Late Failure of Dental Implant-A Systematic Review of Recent Studies. Int. J. Environ. Res. Public Health 2020, 17, 3931. [CrossRef] [PubMed]

23. Nastri, L.; Moretti, A.; Migliaccio, S.; Paoletta, M.; Annunziata, M.; Liguori, S.; Toro, G.; Bianco, M.; Cecoro, G.; Guida, L.; et al. Do Dietary Supplements and Nutraceuticals Have Effects on Dental Implant Osseointegration? A Scoping Review. Nutrients 2020, 12, 268. [CrossRef] [PubMed]

24. Dogan, A.; Yalvac, M.E.; Sahin, F.; Kabanov, A.V.; Palotas, A.; Rizvanov, A.A. Differentiation of human stem cells is promoted by amphiphilic pluronic block copolymers. Int. J. Nanomed. 2012, 7, 4849-4860. [CrossRef]

25. Akash, M.S.H.; Rehman, K. Recent progress in biomedical applications of Pluronic (PF127): Pharmaceutical perspectives. J. Control. Release 2015, 209, 120-138. [CrossRef]

26. Cidade, M.; Ramos, D.J.; Santos, J.; Carrelo, H.; Calero, N.; Borges, J.P. Injectable Hydrogels Based on Pluronic/Water Systems Filled with Alginate Microparticles for Biomedical Applications. Material 2019, 12, 1083. [CrossRef]

27. Ahmed, E.; Hyun, L.D.; Wang, W.C.W.; Choon, C.S. The Survival Rate of RBM Surface versus SLA Surface in Geometrically Identical Implant Design. J. Oral Biol. 2014, 1, 8.

28. Sargeant, T.D.; Guler, M.O.; Oppenheimer, S.M.; Mata, A.; Satcher, R.L.; Dunand, D.C.; Stupp, S.I. Hybrid bone implants: Self-assembly of peptide amphiphile nanofibers within porous titanium. Biomaterials 2008, 29, 161-171. [CrossRef]

29. Jemat, A.; Ghazali, M.J.; Razali, M.; Otsuka, Y. Surface Modifications and Their Effects on Titanium Dental Implants. BioMed Res. Int. 2015, 2015, 791725. [CrossRef]

30. Wang, Q.; Zhou, P.; Liu, S.; Attarilar, S.; Ma, R.L.; Zhong, Y.; Wang, L. Multi-Scale Surface Treatments of Titanium Implants for Rapid Osseointegration: A Review. Nanomaterials 2020, 10, 1244. [CrossRef]

31. Fouziya, B.; Uthappa, M.A.; Amara, D.; Tom, N.; Byrappa, S.; Sunny, K.; Nagaraj, T. Surface modifications of titanium implants-The new, the old, and the never heard of options. J. Adv. Clin. Res. Insights 2016, 3, 215-219. [CrossRef]

32. Strnad, G.; Chirila, N.; Petrovan, C.; Russu, O. Contact Angle Measurement on Medical Implant Titanium Based Biomaterials. Procedia Technol. 2016, 22, 946-953. [CrossRef]

33. Li, X.; Xu, H.; Zhao, B.; Jiang, S. Accelerated and enhanced osteointegration of MAO-treated implants: Histological and histomorphometric evaluation in a rabbit model. Int. J. Oral Sci. 2018, 10, 11. [CrossRef] [PubMed]

34. Abdulmajeed, A.A.; Lassila, L.V.; Vallittu, P.K.; Närhi, T.O. The Effect of Exposed Glass Fibers and Particles of Bioactive Glass on the Surface Wettability of Composite Implants. Int. J. Biomater. 2011, 2011, 607971. [CrossRef] [PubMed]

35. Koca, R.B.; Güven, O.; Çelik, M.S.; Furatlı, E. Wetting properties of blood lipid fractions on different titanium surfaces. Int. J. Implant. Dent. 2020, 6, 16. [CrossRef] [PubMed]

36. Russo, E.; Villa, C. Poloxamer Hydrogels for Biomedical Applications. Pharmaceutics 2019, 11, 671. [CrossRef]

37. Laftah, W.A.; Hashim, S.; Ibrahim, A.N. Polymer Hydrogels: A Review. Polym. Technol. Eng. 2011, 50, 1475-1486. [CrossRef]

38. Hong, J.; Kurt, S.; Thor, A. A Hydrophilic Dental Implant Surface Exhibits Thrombogenic Properties In Vitro. Clin. Implant. Dent. Relat. Res. 2013, 15, 105-112. [CrossRef]

39. Chiang, H.-J.; Chou, H.-H.; Ou, K.-L.; Sugiatno, E.; Ruslin, M.; Waris, R.A.; Huang, C.-F.; Liu, C.-M.; Peng, P.-W. Evaluation of Surface Characteristics and Hemocompatibility on the Oxygen Plasma-Modified Biomedical Titanium. Metals 2018, 8, 513. [CrossRef]

40. Park, J.Y.; Davies, J.E. Red blood cell and platelet interactions with titanium implant surfaces. Clin. Oral Implant. Res. 2000, 11, 530-539. [CrossRef] 
41. Cicciu', M.; Fiorillo, L.; Herford, A.; Crimi, S.; Bianchi, A.; D'Amico, C.; Laino, L.; Cervino, G. Bioactive Titanium Surfaces: Interactions of Eukaryotic and Prokaryotic Cells of Nano Devices Applied to Dental Practice. Biomedicines 2019, 7, 12. [CrossRef]

42. Cometa, S.; Bonifacio, M.A.; Ferreira, A.M.; Gentile, P.; De Giglio, E. Surface Characterization of Electro-Assisted Titanium Implants: A Multi-Technique Approach. Materials 2020, 13, 705. [CrossRef] [PubMed]

43. Gioffredi, E.; Boffito, M.; Calzone, S.; Giannitelli, S.M.; Rainer, A.; Trombetta, M.; Mozetic, P.; Chiono, V. Pluronic F127 Hydrogel Characterization and Biofabrication in Cellularized Constructs for Tissue Engineering Applications. Procedia CIRP 2016, 49, 125-132. [CrossRef]

44. Abdullin, T.I.; Bondar, O.V.; Shtyrlin, Y.G.; Kahraman, M.; Çulha, M. Pluronic Block Copolymer-Mediated Interactions of Organic Compounds with Noble Metal Nanoparticles for SERS Analysis. Langmuir 2010, 26, 5153-5159. [CrossRef] [PubMed]

45. Hecker, M.; Ting, M.; Malmström, J. Simple Coatings to Render Polystyrene Protein Resistant. Coatings 2018, 8, 55. [CrossRef]

46. Reis, R.C.N.; Oda, S.C.; De Almeida, M.V.; Lourenco, M.C.S.; Vicente, F.R.C.; Barbosa, N.R.; Trevizani, R.; Santos, P.L.C.; Le Hyaric, M. Synthesis and antimicrobial activity of amphiphilic carbohydrate derivatives. J. Braz. Chem. Soc. 2008, 19, 1065-1072. [CrossRef]

47. Liu, H.; Li, W.; Liu, C.; Tan, J.; Wang, H.; Hai, B.; Cai, H.; Leng, H.J.; Liu, Z.J.; Song, C.L. Incorporating simvastatin/poloxamer 407 hydrogel into 3D-printed porous Ti $6 \mathrm{Al} 4 \mathrm{~V}$ scaffolds for the promotion of angiogenesis, osseointegration and bone ingrowth. Biofabrication 2016, 8, 045012. [CrossRef]

48. Aw, M.S.; Gulati, K.; Losic, D. Controlling Drug Release from Titania Nanotube Arrays Using Polymer Nanocarriers and Biopolymer Coating. J. Biomater. Nanobiotechnol. 2011, 2, 477-484. [CrossRef]

49. Kondiah, P.J.; Kondiah, P.P.D.; Choonara, Y.E.; Marimuthu, T.; Pillay, V. A 3D Bioprinted Pseudo-Bone Drug Delivery Scaffold for Bone Tissue Engineering. Pharmaceutics 2020, 12, 166. [CrossRef]

Publisher's Note: MDPI stays neutral with regard to jurisdictional claims in published maps and institutional affiliations.

(C) 2020 by the authors. Licensee MDPI, Basel, Switzerland. This article is an open access article distributed under the terms and conditions of the Creative Commons Attribution (CC BY) license (http://creativecommons.org/licenses/by/4.0/). 